\title{
A identidade teuto-brasileira pensada pelo intelectual Alous Friederichs
}

Haike Roselane Kleber da Silva*

Resumo. O grupo étnico teuto-brasileiro produziu, no sul do Brasil, diversas lideranças em diferentes âmbitos do viver social. Essas lideranças foram responsáveis, por sua vez, pela produção e reprodução de interpretações sobre seu grupo étnico e sobre os outros. Este artigo analisa o discurso de J. Aloys Friederichs - uma liderança étnica teuto-brasileira - a respeito da identidade de seu grupo.

Palavras-chave: Germanidade. Etnicidade. Liderança étnica.

Neste artigo, proponho-me a analisar a identidade teutobrasileira, mais propriamente as interpretações sobre a identidade dos imigrantes alemães e seus descendentes, formuladas por uma intelectualidade interna ao grupo étnico que atuou também como liderança entre o final do século XIX e as primeiras décadas do

* Doutora em História pela UFRGS. As traduções das citações foram feitas pela autora, com correção de Walter Volkmann.

Anos 90, Porto Alegre, v. 12, n. 21/22, p.295-330, jan./dez. 2005 
A identidade teuto-brasileira pensada pelo intelectual Aloys Friederichs

XX no sul do Brasil. Esta análise divide-se em três partes: uma teórica, na qual discuto a identidade teuto-brasileira como conceito; em seguida, trato de alguns intelectuais e lideranças do grupo étnico, e, por fim, do pensamento de J. Aloys Friederichs.

A pergunta que envolve este trabalho não é nada inédita ${ }^{1}$ "como se caracteriza a identidade teuto-brasileira ou o grupo ao qual ela pertence?" -, mas certamente o debate ainda não se encerrou. Por isso, proponho refletir a respeito, demarcando, inicialmente, as fronteiras do que considero a compreensão acadêmica dessa identidade em relação ao entendimento produzido pelo próprio grupo étnico, mais propriamente por seus intelectuais. A primeira - à qual incluo minha análise - percebe a identidade teutobrasileira como resultado de um processo de assimilação (Willems, 1980), sincretismo cultural (Meyer, 2000) ou como produto de uma ideologia étnica (Seyferth, 1981). A segunda compreende-a como uma identidade dual, cujo elemento étnico alemão era imutável, herdado, permanente e de valor positivo, e a condição de brasileiro uma contingência reservada para o âmbito dos direitos e deveres de cidadão. A primeira busca seu espaço no debate acadêmico. A segunda teve seu espaço no grupo étnico, talvez mais restrito do que imaginou conquistar.

\section{A identidade}

Compreendo esse adjetivo composto como um referencial de identidade étnica, tomando como parâmetro de análise as perspectivas de Fredrik Barth e Max Weber a respeito dos grupos étnicos, principalmente com relação ao peso que é dado à subjetividade (no sentido de crença subjetiva) nos processos de demarcação da etnicidade. Barth propõe uma definição de que os grupos étnicos surgem da interação social, a qual resulta em processos de inclusão e exclusão e, conseqüentemente, no estabelecimento de 
Haike Roselane Kleber da Silva

fronteiras. Para a delimitação das fronteiras, entram em questão traços escolhidos pelo próprio grupo que serão operativos para estabelecer o contraste (Poutignat; Streiff-Fenart, 1988). Na esteira das idéias de Barth, Poutignat e Streiff-Fenart (ibid., p.12), acrescentaram à teoria das fronteiras demarcatórias a questão específica da etnicidade, ou seja, "a fixação de símbolos identitários que fundam a crença em uma origem comum". Tais símbolos são buscados na memória coletiva, no passado, numa história mítica, criando um sentido comum de identidade grupal.

A crença na origem comum, no entanto, já aparece nas reflexões de Weber (1994) sobre o tema. Alguns fatores ou traços culturais comuns à comunidade podem atuar como elementos de distinção entre os grupos, mas esses só alimentam as fronteiras que a crença na origem demarcou. Se esse é o elemento inicial de demarcação do grupo étnico, sua sobrevivência ou manutenção depende do estabelecimento de traços que o distinguirão mais objetivamente dos outros. Esses traços podem mudar no decorrer da existência ou serem diferentes de acordo com outras categorias classificatórias dentro do mesmo grupo étnico. As características comuns, os fatores de diferenciação, ou hábitos e costumes dão suporte ao que, na visão de Weber, realmente sustenta a identidade do grupo: a "honra étnica", ou seja, a percepção da superioridade das características de cada grupo étnico.

Nesse sentido, a identidade teuto-brasileira, como uma identidade étnica, caracteriza-se pela seleção, por parte do grupo, de uma série de traços culturais que buscam identificar as pessoas que o integram, como a língua, hábitos, instituições típicas, além do ethos do trabalho, traços estes que materializam a crença numa origem e num passado comum. Esses traços são ressaltados em diferentes momentos, ora um ora outro, de acordo com a dinamicidade histórica e com a intensidade do contato com outros grupos que compõem a diversidade étnica do sul do Brasil, e 
A identidade teuto-brasileira pensada pelo intelectual Aloys Friederichs

cumprem a função de símbolos identitários. $\mathrm{Na}$ busca da identificação, são desconsideradas diferenças preexistentes, características de processos anteriores de delimitação grupal.

Assim, a população imigrante de origem alemã desenvolveuse, desde os primeiros anos da colonização, como grupo étnico. Compunham um grupo heterogêneo, com identidades religiosas diferenciadas, provindo de regiões diversas de um país que, nos primórdios da imigração, não havia se constituído como EstadoNação unificado (Woortmann, 2000). Essa heterogeneidade se amplia no caso de regiões de colonização mista, onde grupos não alemães (poloneses e russos, por exemplo) eram identificados pelos brasileiros como se fossem alemães e passaram, com o decorrer do tempo, a se auto-identificarem como tal. Mesmo que se encontrassem, nos anos iniciais, em relativo isolamento, o fator isolamento/enquistamento não foi tão decisivo para a formação de uma identidade grupal; mas sim, pelo contrário, foi no contraste entre as culturas européia e brasileira que se constituiu a etnicidade.

Esse entendimento do que seja e de como tenha se formado a identidade teuto-brasileira foi construído a posteriori sobre bases do pensamento antropológico e diferencia-se daquele elaborado e difundido pelos intelectuais do grupo étnico, cujo aporte principal era o germanismo. Para este, a identidade teuto-brasileira é composta de dois elementos: um relativo à fidelidade étnica e cultural e outro à fidelidade política. A etnicidade, na compreensão dos germanistas, é primordialista e está embutida na noção de Volkstum, que é a essência da qual é formado o povo que, por seu lado, constitui uma nação. Essa essência é compreendida como caráter nacional e, às vezes, como etnicidade, dentro de uma perspectiva difundida no século XIX e reapropriada pelos ideólogos do germanismo. Por isso, a identidade teuto-brasileira, na análise de seu primeiro elemento (a identidade teuta), caracteriza-se como étnico-nacional: 
[...] no nacionalismo étnico alemão a identidade étnica e a nacional estão imbricadas, sendo a primeira o suporte e a constituição da segunda. Nesse nacionalismo, o conceito de povo e nação repousa sobre a idéia de uma comunidade de descendência. (Grützmann, 2003b, p.117).

Apesar dos diferentes matizes que compreendem o germanismo, este se baseia em noções como as destacadas por Grützmann (2003b, p.117): povo como unidade primordial, homogênea, orgânica, "unida por laços culturais e biológicos, na qual predomina o princípio da descendência", vínculos de afeto, sangue, língua, além de um passado comum - nem todos acionados ao mesmo tempo ou por todos os germanistas com a mesma ênfase. Nesse ideário, são apropriadas do nacionalismo alemão duas expressões básicas: Volkstum, entendido como a essência do povo, o caráter, "tudo o que concerne à filiação de um determinado povo", também etnicidade (tomada como identidade primordial de um grupo), e Deutschtum (germanidade) como a essência do povo alemão. Essas duas palavras servem de matriz para uma série de outras, produzidas e reproduzidas pelo discurso germanista, algumas delas específicas à situação vivida no Brasil - como, por exemplo, Deutschbrasilianertum, ou identidade teuto-brasileira. Para o germanismo, a língua é "um fator determinante da germanidade" e "seu guardião", e, por esta premissa além dos vínculos de descendência, "todos os imigrantes e seus descendentes residentes fora das fronteiras da Alemanha integram o povo alemão". O discurso germanista prega a identificação com o Brasil apenas no plano político e econômico Em conseqüência, não aceita qualquer proposta assimilacionista, "desconsidera a integração à cultura brasileira e a adoção de traços culturais que pudessem transformar essa matriz original por eles idealizada".

Os ideais de cultivo do Deutschtum e, ao mesmo tempo, de amor à pátria brasileira - uma variação, a meu, ver, da identificação apenas política e econômica - estiveram presentes no discurso de 
A identidade teuto-brasileira pensada pelo intelectual Aloys Friederichs

parte da intelectualidade teuta. Apesar da maciça produção cultural voltada à preservação da germanidade, não se deve, no entanto, tomar o discurso das lideranças teuto-brasileiras como exemplo para avaliar a população em geral, mas como iniciativas de uma intelectualidade (Gertz, 1994). Gertz (1998) é ainda mais enfático ao afirmar a existência de "abismos" entre os discursos dos ideólogos do germanismo e as concepções encarnadas pela população teuta. Quer dizer com isso que o germanismo não influenciou a comunidade alemã em bloco, e que considera um erro tomar o discurso dos agentes - ou dos intelectuais - como a realidade de posicionamento de todo o grupo. É preciso, portanto, fazer diferença entre o teuto-brasileiro idealizado pelo germanismo e aquele fruto do processo migratório, marcado pela colonização e pela "negociação" (Lesser, 2001) na construção de uma identidade hifenizada.

\section{Os que pensaram a identidade}

A população imigrante alemã, desde sua chegada ao Brasil, mas principalmente a partir de meados do século XIX, constituiuse como grupo étnico, ressaltando por vezes as diferenças lingüísticas, em outras o fenótipo em comparação com os nativos do Brasil, ou as diferenças religiosas, as relações familiares e de trabalho. Muitas das características de distinção foram sendo substituídas com o passar do tempo, outras sendo agregadas, algumas mais fortemente ressaltadas na medida em que o grupo demarcava seus limites à integração. Como grupo distinto, ele também produziu suas lideranças, que atuaram em diferentes campos - religioso, político, social - concomitantemente ou em diferentes épocas, com preocupações que ora se encontravam e ora divergiam. Em comum, no entanto, todos tiveram o foco de atenção sobre a situação da população de origem imigrante alemã. 
Entre as diferenças, Dreher (2001, p.8) aponta três delas que se referem à filiação filosófico-religiosa da população. Assim, entre os liberais, surge a liderança de Karl von Koseritz; entre os luteranos evidenciam-se, sobretudo, os pastores Wilhelm Rotermund e Hermann Dohms, e entre os católicos são os sacerdotes jesuítas que assumem o papel de mentores do grupo teuto, com maior destaque para figuras de Theodor Amstad e Max von Lassberg. Outros critérios ainda podem ser utilizados para verificar o surgimento de lideranças no seio desse grupo. Interessado

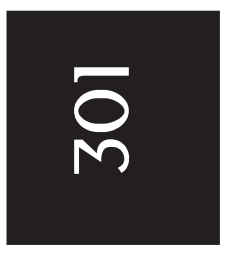
pela integração política dos teutos, Gertz (1987, p.34) atribui à "geração de 48" importante papel de liderança. Estes teriam saído da Alemanha com maior nível social e cultural que os primeiros emigrantes ou com experiência no âmbito da política e da guerra. Atuaram como porta-vozes da população teuta no Rio Grande do Sul na luta pela participação política. Entre essas lideranças, o mais conhecido é Karl von Koseritz, "figura-símbolo desse grupo". Como redator de jornal, buscou dar voz à necessidade de integração política dos teutos, sobretudo da população rural, trabalhando por modificações na legislação brasileira que lhes permitissem participar do processo político. Nesse sentido, Koseritz constitui-se como liderança no campo da política - a principal no século XIX - ocupando, além disso, um espaço de representação dos interesses do grupo étnico na Assembléia Provincial. Na tribuna, pleiteava melhores condições para o desenvolvimento econômico desse grupo e a garantia de seus direitos civis e políticos (Gans, 2004, 137). Sua liderança foi ainda mais além. Como intelectual e jornalista, propunha a formação de uma nova identidade para os alemães imigrantes, uma identidade "genuinamente teutobrasileira", insistindo na dualidade cidadania brasileira e nacionalidade alemã (idem). Por isso foi denominado o pai do teutobrasileirismo. Para Gans (2004, p.137), sua maior importância está aí: 
A identidade teuto-brasileira pensada pelo intelectual Aloys Friederichs

Talvez justamente por ele ter proposto uma postura de maior adaptação pragmática ao contexto em que estavam inseridos os teutos no Brasil, de modo a estes obterem os benefícios da cidadania, tenha contribuído efetivamente para a constituição de uma identidade teuto-brasileira na qual a porção teuta, mesmo que metamorfoseada, persistisse por tanto tempo.

A diferença entre Koseritz e outros ideólogos do germanismo, principalmente daquele que viria a predominar no século XX, estaria na ênfase dada à integração cívica e política, o que lhe rendeu severas críticas, anos mais tarde, por parte dos germanistas da década de 30. Segundo Oberacker (apud Gertz, 1999, p.8), por exemplo,

[...] a fraqueza do liberalismo de Koseritz se fundamenta na sua incapacidade de reconhecer a importância do sangue e da raça. Por isso ele também foi incapaz de proclamar com convicção a imprescindível autopreservação étnica. Enquanto avançava na ocupação do espaço na política do país, afrouxavam-se simultaneamente e em proporções correspondentes seus fundamentos étnicos.

Não foi apenas de seus sucessores, porém, que Koseritz recebeu críticas. Seus posicionamentos também importunaram lideranças religiosas contemporâneas a ele. Isso fica evidente nas afirmações do Deutsche Post (apud Gans, 2004, p.147), jornal de tendência luterana dirigido por Wilhelm Rotermund, quando, em 1882, confirma:

[...] é preciso admitir que Koseritz é o líder. Isso pode ser agradável ou pode ser lamentável. Podemos felicitar a coletividade por esse líder ou podemos cordialmente deplorar esta situação. O fato é que o senhor Koseritz, entre todos, é o que goza de maior confiança dos teutos na Província.

Anos 90, Porto Alegre, v. 12, n. 21/22, p.295-330, jan./dez. 2005 
Por seu lado, Koseritz também desferia críticas ao pastor luterano, como mostra o comentário feito pelo primeiro à decisão de Rotermund de naturalizar-se:

O Sr. Rotermund, cujo jornal, a Deutsche Post, prestou tão estimados serviços à causa da germanidade, quer parar de fazer política platônica e deixou naturalizar-se. Ao amigo um afetuoso aperto de mão por essa decisão. (Gertz, 2002, p.37).

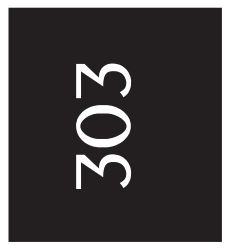

As discussões travadas por Koseritz e Rotermund, em geral nos veículos de imprensa que coordenavam, se constituíam em disputas pela maior influência sobre o elemento germânico. Wilhelm Rotermund construíra sua liderança junto aos imigrantes luteranos, na medida em que trabalhou pela organização da Igreja. Liderou a fundação, em 1886, do Sínodo Riograndense, ${ }^{2}$ sendo presidente da instituição nessa fase até 1893 e mais tarde, de 1909 a 1919. Era reconhecido como representante daquele grupo, como os acontecimentos de 1918 o demonstram. Em janeiro desse ano,

[...] foram proibidos todos os ofícios religiosos em língua alemã, mas já em abril do mesmo ano o chefe de polícia do Rio Grande do Sul recuou um pouco nessa determinação, graças à intervenção pessoal de Rotermund junto a Borges de Medeiros. (Gertz, 2002, p.32).

Como líder eclesiástico, deixou o trabalho em 1919. Rotermund propunha a atrelagem entre igreja e germanidade (identidade étnico-nacional alemã) como algo intrínseco aos dois elementos. Para ele, se os membros da comunidade religiosa luterana abdicassem da sua germanidade, estariam perdidos para a Igreja. De modo inverso, caso deixassem de ser luteranos, estariam também abandonando sua germanidade (Gertz, 2002, p.30). Essa 
A identidade teuto-brasileira pensada pelo intelectual Aloys Friederichs

crítica estendia-se, a meu ver, aos casamentos mistos - entre luteranos e católicos - dentro do grupo étnico.

Além de pastor e liderança eclesiástica, Rotermund destacou-se como editor. Nessa posição, exerceu influência intelectual e política por meio dos impressos que produzia, sobretudo do almanaque Kalender für die Deutschen in Brasilien (com distribuição de 30.000 exemplares em 1923) e do jornal Deutsche Post. Segundo Gertz (2002, p.36), "O jornal refletia muito bem a posição e a atuação políticas do velho Rotermund. A amalgamação entre germanidade, luteranismo e política, certamente, teve na Deutsche Post seu mais típico representante". Há ainda a indicação de sua participação no Partido Colonial' como "mentor intelectual" (Gertz, 2002, p.38).

$\mathrm{Na}$ esteira da obra de Rotermund, surge outra liderança eclesiástica luterana que começa a se destacar assim que este deixa a presidência do Sínodo. Hermann Dohms, nascido brasileiro, mas de formação alemã, inicia seu trabalho como pastor em Cachoeira do Sul, de onde começa também a influenciar no Sínodo RioGrandense. Quando decide pelo pastorado no Brasil, já tem em mente um trabalho mais amplo, como indica a carta que escreveu à sua noiva: "Meu trabalho lá [no Brasil] será belo, porque será maior [do que na Alemanha], não me prenderá aos limites estreitos de minha comunidade, mas me provocará para fazer algo por toda a germanidade no Rio Grande do Sul" (Dohms apud Dreher, 2001, p.16).

A produção intelectual de Dohms era veiculada por meio da Deutsche Evangelische Blätter für Brasilien (Folhas Alemãs Evangélicas para o Brasi), que começou a ser editada em 1919 com a intenção de fomentar o debate de idéias (Dreher, 2001, p.16). Sua preocupação também se voltava à inserção dos teutos na sociedade brasileira sem "abandonar o legado cultural de seus antepassados" (ibid., p.18). Dohms envolveu-se diretamente com o trabalho administrativo da Igreja, tornando-se presidente do Sínodo em 1935.

Anos 90, Porto Alegre, v. 12, n. 21/22, p.295-330, jan./dez. 2005 
Segundo Dreher (2001, p.28), "sua habilidade de negociador, mas também sua firmeza evitou a cisão do Sínodo e, além disso, levaram à dissolução do Pastorado Nacional-Socialista e do Movimento dos Teuto-Cristãos do Brasil”.

$\mathrm{Na}$ liderança dos teutos católicos, consagraram-se nomes como os dos sacerdotes jesuítas Gasper, Amstad, Rick e Lassberg, entre outros. Com a montagem de um sistema associativo, a Igreja Católica mobilizou os colonos a desenvolverem-se economicamente e a permanecerem no campo. Os padres que mais tiveram influên-

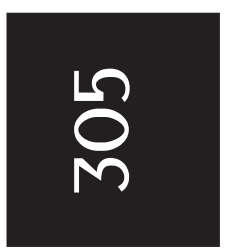
cia sobre a população teuta foram aqueles que assumiram posições de comando nessas associações, em geral como Reisesekretär (secretário de viagem), que percorriam o interior com suas idéias em lombo de mula, expandindo a influência do catolicismo jesuítico. Como atesta Félix (1994, p.83-84), "alguns tinham acesso ao governador do Estado, como por exemplo, o padre Rick, que visitava constantemente Borges de Medeiros e detinha poder de barganha".

Para além dos grupos definidos por Dreher, de identificação filosófico-religiosa, o grupo étnico teuto desenvolveu lideranças em diferentes classes sociais. Entre os operários, por exemplo, ressalta-se a atuação de Friedrich Kniestedt nas décadas de 1920 e 1930. Kniestedt dirige a Sozialistischer deutscher Arbeitverein, uma associação de cunho anarquista reconhecida como a principal representante dos operários teutos (Gertz, 1986, p.77), redige o jornal Der freie Arbeiter (na década de 20) e Aktion (na década de 30). Sua militância operária tinha também um cunho étnico e procurava atrair a população da região de colonização alemã para sua causa sempre que por lá passava. Por outro lado, sofria forte oposição no círculo étnico, como demonstra Gertz (1986, p.80):

Em todos os lugares por que passava [São Leopoldo, Montenegro, Neu-Württemberg], criava grupos de "freie Arbeiter" (trabalhadores livres). Este tipo de ação resultava 
A identidade teuto-brasileira pensada pelo intelectual Aloys Friederichs

em oposição férrea por parte dos representantes tradicionais da "colônia alemã". A Neue Deutsche Zeitung, de Porto Alegre, não perdia oportunidade para acusar Kniestedt de bolchevista e judeu - ele fazia questão de dizer que não era um nem outro -, de terrorista etc. Pastores luteranos manifestavam-se freqüentemente contra a sua atividade.

É de se destacar também a liderança de Arno Philipp, político teuto que assumiu posição no parlamento rio-grandense entre os anos de 1905 e 1928. Durante a Primeira República, foi o único imigrante alemão a ocupar tal posto. Como político e redator do Deutsche Zeitung, defendeu a necessidade da aproximação entre "germanidade" e "brasilidade" (Brepohl, 1930, p.149-150). Outra liderança que, assim como Arno Philipp, se destacou como um "político profissional" foi Alberto Bins (Gertz, 1998, p.27). Este ocupou o posto de intendente municipal de Porto Alegre entre os anos de $1928^{4}$ e 1937. Enquanto industrial, constituiu-se também de uma liderança empresarial bastante atuante no sentido da mobilização de sua classe.

Outros nomes podem ainda ser lembrados, com atuação em diferentes campos, na cidade e na zona rural, o que não cabe, no entanto, aos objetivos deste artigo. É possível verificar alguns pontos de convergência entre as diferentes lideranças citadas. Um deles é a atividade intelectual na redação ou edição de jornais voltados ao público de língua alemã. A partir deles, aqueles conseguiam divulgar suas idéias, fazer ouvir seus discursos, influenciar leitores, angariar aliados e opositores.

Com exceção de Kniested - que parece preocupar-se mais com a conversão da população teuta ao anarquismo, sendo a identificação étnica apenas um modo de aproximação -, todos os demais demonstram um intenso empenho pela demarcação dos limites do grupo teuto ou teuto-brasileiro, pela caracterização desta identidade, pela definição dos aspectos a serem preservados e dos aspectos a serem assimilados. No entanto, a atuação como lide- 
ranças em campos distintos - político, religioso, social -, em épocas diferentes, sob influências externas também diferentes, produziram percepções de nuances diversos sobre esse tema. Esses matizes impedem a compreensão da identidade teuto-brasileira como uma proposição uniforme para todo o grupo étnico.

Outra questão importante é o alcance dessas proposições formuladas pelas lideranças, das idéias veiculadas por eles, da recepção do discurso, enfim, do controle exercido sobre o "rebanho". Neste sentido, Gertz (1994, p.31) posiciona-se com o se-

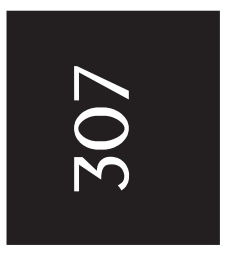
guinte:

\begin{abstract}
Mas mesmo que alguns intelectuais de origem alemã não estivessem tão distanciados do conjunto da população quanto Oberacker, tem-se superestimado o controle das lideranças. Mesmo padres e pastores estavam muito longe de exercer um controle total, como muitas vezes se pensa. As dificuldades que enfrentavam eram muito grandes. Desta forma, deve ser muito relativizado o conteúdo do discurso desses agentes.
\end{abstract}

Concordo no aspecto relativo do controle das lideranças sobre seus círculos de influência - levando em conta a liberdade dos indivíduos de conduzirem suas próprias trajetórias. A emergência de diferentes lideranças também remete a isso. Por outro lado, estes indivíduos foram construindo a confiança, a credibilidade, a fidelidade de seus liderados, o que permite entender que havia quem os ouvisse e, inclusive, obedecesse. Deve-se ainda ter em mente que a massa documental é produzida pelas lideranças, o que conduz à leitura da realidade na sua perspectiva. É importante, no entanto, estar ciente de que é uma perspectiva e que buscou ser aceita na época.

Entre os diferentes campos nos quais surgiram lideranças dentro do grupo teuto-brasileiro, é de se destacar as sociedades recreativas. Espaço de preservação de identidades, de constituição 
A identidade teuto-brasileira pensada pelo intelectual Aloys Friederichs

de lealdades, de representação de grupos sociais, os clubes em geral e as sociedades recreativas teutas em particular eram também espaços de construção de lideranças. Entre estas, o Turnerbund de Porto Alegre teve relativo destaque, não apenas por ser a mais antiga sociedade de ginástica do Estado, mas também por seu expressivo trabalho em prol da germanidade. Em contrapartida, a população de origem germânica da capital tinha no Turnerbund uma referência, apoiando suas ações, participando ativamente das aulas de ginástica, enchendo o seu parque aos domingos ou o salão nas peças teatrais. Esta instituição era considerada pelo Koseritz. Deutsche Zeitung, já em 1895, a sociedade de maior florescimento de todas as sociedades teuto-brasileiras (Koseritz, 1895). Nela se realizavam as festas em homenagem ao aniversário do Imperador alemão, ao Deutscher Tag, ao Centenário da Independência do Brasil, ao Centenário da Imigração Alemã e outras mais que reuniam grande parte da população teuta da capital e também do interior. Além disso, era a principal associação esportiva e social da elite teuto-brasileira de Porto Alegre, onde, como afirma Fortes (2004, p.183), "se reuniam os jovens para a prática da ginástica, mas também discursavam políticos e articulistas". Nota-se aí a conjunção de interesses que envolviam a formação de espaços de sociabilidade como os clubes recreativos do grupo étnico alemão.

Se o Turnerbund era referência para o associativismo teuto, de igual importância se revestiam os dirigentes desta instituição. Dos primeiros 50 anos de existência do Turnerbund, mais de 30 deles tiveram J. Aloys Friederichs ${ }^{5}$ como a figura central. $\mathrm{Na}$ verdade, pode-se dizer que estes dois nomes sempre estiveram muito ligados. A Friederichs se confere a responsabilidade pela fundação do Turnerbund, resultado da unificação das duas sociedades de ginástica existentes em Porto Alegre antes de 1892. A ele também se atribui o crescimento da sociedade nos primeiros 30 anos. Sua saída da presidência, em 1929, foi interpretada como "um acontecimento na história da sociedade", pois iria ser eleito, então "um 
presidente que não se chama Aloys Friederichs" (Turnerbund, 16 dez. 1929). Mesmo depois de seu afastamento, era consultado e chamado a opinar nos momentos importantes. Já na sua velhice, vê o nome Turnerbund ser também aposentado pela história.

Dando atenção especial à prática do Turnen (ginástica alemã) Friederichs foi associado à figura de Friedrich Ludwig Jahn, ideólogo do nacionalismo alemão, o "pai da ginástica". Aloys é então considerado o Riograndenser Turnvater ou "pai da ginástica no Rio Grande do Sul". Em 1901, é possível encontrar a primeira referência na imprensa ao reconhecimento de seu papel como sucessor de Jahn no além-mar. Ele é considerado então o "Jahn da nova Pátria” (Koseritz Deutsche Zeitung, 20 nov. 1901). Já nessa época, era visto como "o homem com o autêntico coração alemão" (ibid., 21 abr. 1902), o que mostra também a identificação direta de sua pessoa com o cultivo da germanidade. A partir de suas posturas pessoais e sua atuação pública, Friederichs era representado, no auge de sua liderança na década de 20, como “o homem mais influente e ativo" no que se refere ao trabalho pelo bom relacionamento entre lusos e teutos, pela preservação da língua alemã e pela germanidade (Ammon, 1922). No Deutsche Post (3 fev. 1928), jornal publicado em São Leopoldo, Friederichs aparece como "a personificação do pensamento alemão. Aos olhos da imprensa em língua portuguesa, na mesma época, destacava-se sua atuação como fomentador do esporte, como "um dos desportistas que mais tem feito pela ginástica entre nós" (Correio do Povo, 3 fev. 1928); mas também é denominado "paredro da colônia alemã" (Diário de Notícias, 3 fev. 1928). ${ }^{6}$ Olhos externos também evidenciavam a liderança e influência de Friederichs, como expresso num jornal argentino em língua alemã que o considerava "o homem mais alemão do Rio Grande do Sul" (Deutsche Wacht, 13 fev. 1923). Essas e outras evidências, confirmam a atuação de Jacob Aloys Friederichs como uma liderança entre os teutos. 
A identidade teuto-brasileira pensada pelo intelectual Aloys Friederichs

Enfim, se o associativismo tinha destacada importância para os teutos e o Turnerbund a mesma posição entre as sociedades recreativas, liderar esta sociedade por mais de 3 décadas também parece ter muita significação. Se o Turnerbund teve expressivo papel em prol da germanidade - até por ser a ginástica uma atividade nascida de dentro do nacionalismo alemão - e as sociedades recreativas em geral servirem de pilares da preservação identitária na ótica germanista, ao lado da escola comunitária teuta e do catolicismo e luteranismo de imigração, é compreensível e bastante provável que uma liderança associativa também acabasse por ser uma liderança étnica.

\section{O germanismo em tese e o germanismo de Friederichs}

Como liderança étnica, Friederichs pode ser considerado um intelectual teuto-brasileiro. Sua trajetória ficou marcada pela preocupação com a inserção da população imigrante alemã e de seus descendentes na sociedade brasileira - ou seja, no que permanecer alemão e no que assumir uma identidade brasileira - a partir de uma concepção de etnicidade, de herança cultural, de nação, de deveres e obrigações, de lealdades e fidelidades com profundas raízes fincadas no nacionalismo alemão. Como germanista, formulou proposições para a construção de uma relação dos "de origem" alemã com sua cultura ancestral e com sua nova pátria. Tais proposições podem ser encontradas nas publicações que lançou, assim como nas cartas que escreveu a amigos, parentes, correligionários e opositores. Mais formais - como as publicações impressas -, ou menos formais - como as cartas pessoais -, os escritos de Friederichs expunham seu ponto de vista, às vezes com apelos inflamados, estabeleciam debates com outras lideranças, provocavam alianças, adesões e contestações. A palavra escrita - pública ou particular - foi um veículo especialmente utilizado para reforçar

Anos 90, Porto Alegre, v. 12, n. 21/22, p.295-330, jan./dez. 2005 
seu ideal de identidade para os teutos no Brasil, em certos aspectos tão marcadamente alemão, em outros beirando a assimilação.

Se Friederichs foi um dos ideólogos do germanismo no Sul do Brasil - como afirmado por Grützmann (1999) -, é importante definir, afinal, o que isso significava efetivamente. Considerando o germanismo um movimento intelectual, uma ideologia, uma forma de interpretação específica, ser seu ideólogo denota uma posição de ponta na proposição de idéias e não apenas a reprodução de um discurso formulado por outros. Mesmo como liderança de

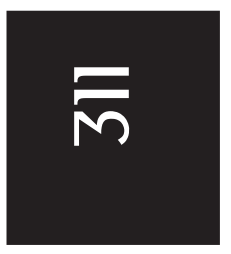
um movimento intelectual, no entanto, Friederichs compartilhava princípios com os demais germanistas, o que lhes permite serem vistos como um movimento, um tipo de interpretação, uma ideologia característica. Por isso, retomo alguns dos preceitos básicos desta ideologia para colidi-los com o germanismo manifestado nos escritos de Friederichs.

O germanismo é um movimento intelectual surgido entre meados do século XIX e a década de 1940 entre indivíduos do grupo étnico alemão no Brasil, tendo como preocupação central a defesa da identidade étnico-nacional da população imigrante. ${ }^{7}$ Foi encabeçado por figuras da elite teuta ${ }^{8}$ - jornalistas, professores, pastores, comerciantes, industriais -, que forjaram uma identidade específica para esta população com base na distinção étnica propriamente etnocêntrica - em que são tomadas características culturais e biológicas como elementos diferenciadores. Como o próprio nome revela, o germanismo não é apenas um movimento de valorização de um caráter, identidade ou modo de ser alemão, mas também tem suas origens numa concepção de unidade cultural germânica própria ao nacionalismo do século XIX. Estes elementos - a identidade alemã e a sua representação ou ideologia nacionalista - são denominados pelo mesmo termo - Deutschtum que, para o germanismo desenvolvido no sul do Brasil também engloba a idéia de "população de origem alemã". Germanismo (a ideologia étnica), germanidade (a identidade, etnicidade, caráter 
A identidade teuto-brasileira pensada pelo intelectual Aloys Friederichs

ou essência do povo alemão) e a população de alemães e seus descendentes no Brasil são identificados no discurso germanista pela mesma palavra, que fornece a raiz para a formação de uma especificidade brasileira: o Deutschbrasilianertum (a identidade ou etnicidade teuto-brasileira).

As idéias que compõem o germanismo advêm, de um modo geral, do romantismo alemão, que serviu de alicerce para a formação de um sentimento nacional, um desejo de unidade como nação, a base do nacionalismo alemão do século XIX. Os românticos buscaram na língua o elo de ligação do povo germânico, traço comum aos indivíduos da nação alemã, uma idéia de nação cultural que não previa a unificação política. Com a dominação francesa a partir de 1806, inicia-se um novo momento para o desenvolvimento das idéias nacionalistas, no qual a coesão nacional de caráter político passa a ser idealizada (Seyferth, 1981, p.21). É nesse momento que Friedrich Ludwig Jahn cunha o termo Volkstum (caráter nacional, etnia) e propõe o Turnen como atividade pedagógico-patriótica. A unificação começa a ser pensada, desejada e elaborada, sem que haja, contudo, uma proposta de consenso para a constituição de um Estado. No entanto, a idéia de nação de nada dependia da existência ou não de um Estado alemão, na medida em que ambos eram entidades completamente distintas nesta tradição. A nação deveria estar circunscrita a todos os povos de língua alemã, permanecendo então um critério lingüístico como princípio da nacionalidade. No início do século XIX, esta idéia, contudo, não ultrapassava as fronteiras sociais de uma elite letrada, uma comunidade intelectual que buscava falar o mesmo idioma, construir uma língua nacional (Schulze, 1997, p.159). Fica claro, então, que quem "imagina" a nação alemã é uma intelectualidade burguesa.

Deste modo, o nacionalismo alemão foi gestado a partir de um movimento literário e cultural, somando-se a isso uma reação ao domínio francês napoleônico. Elaborou as noções de Volkstum 
(etnia, caráter nacional), Deutschtum (caráter nacional alemão) como articuladores de uma unidade baseada na língua e tudo o mais que estava interligado a ela: literatura, música, folclore. Mais para o fim do século XIX, outros ingredientes foram adicionados ao conjunto de idéias que formavam a ideologia nacionalista, sendo temperada por teorias evolucionistas e raciais, ou pela noção de superioridade ariana e anti-semitismo (Grützmann, 2003b, p.118). Não compunham, contudo, o nacionalismo dos pensadores da nação do início do século. Havia sim um etnocentrismo, uma noção de superioridade do "povo alemão", que não se pautava por critérios raciais, porém lingüísticos e de descendência. Uma percepção culturalista, em que traços como a língua e costumes diferenciam o grupo, é somada à percepção primordialista da etnicidade, em que a descendência, os laços familiares, os vínculos de sangue distinguem quem faz parte da etnia e, conseqüentemente, da nação alemã. Sendo assim, na proposta nacionalista deste período, etnia e nacionalidade são dois termos que se fundem nas expressões Volkstum e Deutschtum (germanidade).

No período em que surge o Estado Nacional alemão, em que indivíduos de etnia e nacionalidade alemã se tornam cidadãos alemães, inicia-se também o interesse pelos seus emigrados - irmãos de sangue, etnia e nacionalidade. É, portanto, no fim do século XIX que, entre os alemães de "além-mar", um conjunto de fatores fazem brotar a "reflexão sobre a preservação consciente da germanidade" (Gertz, 1998, p.32): a imigração de cidadãos do Reich para o Brasil; a condução do movimento nacionalista na Alemanha numa linha unificada; a ascensão social de imigrantes, sobretudo no comércio, e o assédio de instituições alemãs voltadas às populações emigradas no sentido de revinculá-las à Alemanha são alguns destes fatores.

O germanismo surge, no Brasil, em meio a uma sociedade multiétnica, na qual a experiência da imigração e da colonização e conseqüentemente do contato interétnico - foi responsável pela 
A identidade teuto-brasileira pensada pelo intelectual Aloys Friederichs

constituição de uma identidade que não se igualava mais à cultura original, nem tão pouco ao ideal nacionalista do que seria um "autêntico" ou "legítimo" alemão. Alguns pesquisadores do tema denominaram de "assimilação" e "aculturação" o processo ocorrido nas "colônias alemãs" do sul do Brasil (Willems, 1980); outros de "sincretismo cultural" (Meyer, 2000); ou de produção de identidade a partir de processos de contato, interação e atribuição (ou autoatribuição) somados a um componente ideológico que resultaria numa ideologia étnica (Seyferth, 1981). A decorrência deste processo, para um ou outro, é um indivíduo com características do grupo original, reforçadas pela oposição nas relações de contato (ou pelo isolamento, em algumas explicações mais tradicionais), e características da sociedade receptora, assimiladas ou aculturadas na negociação da identidade. Disso originou-se o "teuto-brasileiro" ou o "brasileiro-alemão". Este, porém, não é o "teuto-brasileiro" dos germanistas. Para estes, o que ocorria nas "colônias alemãs" do sul do Brasil - de forma inconsciente, desordenada e desorientada - era a perda da matriz essencial da identidade, o abandono dos elementos fundamentais da cultura ancestral. Segundo Grützmann (2003b, p.133),

[...] a denominação "desgermanização" e/ou "abrasileiramento", privilegiada pelos germanistas, não corresponderia a uma perda da identidade, mas sinalizaria a constituição de fronteiras étnicas e padrões culturais entre os imigrantes e seus descendentes, distintos, todavia, dos modelos definidos pelo germanismo.

Sendo assim, o germanismo tinha por objetivo reverter esse processo, restaurar a "autêntica" germanidade entre os imigrantes e seus descendentes, fossem eles alemães naturalizados ou cidadãos nascidos em território brasileiro. De acordo com Grützmann (2003a, p.1), havia por traz disso o intuito dos germanistas de assegurar "seus interesses econômicos e seu poder de comando no

Anos 90, Porto Alegre, v. 12, n. 21/22, p.295-330, jan./dez. 2005 
campo social e cultural, bem como a hegemonia das instituições a que estão filiados", o que caracterizaria o grupo étnico também como "grupo de interesse" (Cohen, 1996). Isso quer dizer que havia, ao lado da busca pela preservação étnica, a necessidade de garantir a distinção do grupo em outros níveis do viver social. Não significa, no entanto, uma determinação do econômico sobre o cultural, ou seja, que os interesses materiais estivessem por trás. A luta pela germanidade constituía-se, isso é visível, numa resistência à assimilação, critério básico para a integração à nação brasileira. Neste propósito, propunham a construção de uma identidade teuto-brasileira em que os elementos de uma e de outra estariam por eles bem definidos. Nesta identidade hifenizada, a porção "teuta" afirmaria a ascendência, a origem étnica e nacional e a lealdade à língua, aos costumes, às instituições, enfim, ao modo de ser alemão. Por definirem, a partir da nação alemã, a nacionalidade por critério de ascendência, consideravam legítimo que os imigrantes assim como seus descendentes - nos quais corre sangue alemão - partilhassem dessa mesma identidade nacional. À porção "brasileira", por outro lado, ficariam garantidas a lealdade política e todas as obrigações que a ligação a um Estado comportam. Do ponto de vista jurídico, esta equação pautava-se no "jus sangüinis", concepção utilizada como critério de nacionalidade até hoje na Alemanha. Tal definição identitária entrava em choque com o princípio jurídico vigente no Brasil para a aquisição da nacionalidade - o "jus solis" - que previa nascimento no território ou naturalização. Mais do que contrariar o princípio oficial, esta formulação proposta pelos germanistas ia de encontro aos fundamentos ideológicos da brasilidade, pautados pela assimilação e eliminação das diferenças étnicas.

Não é possível afirmar que o germanismo foi vitorioso conquistando aceitação da totalidade da população teuta no sul do Brasil. Na avaliação de Gertz (1998, p.45), tudo indica que esta ideologia teve maior aceitação entre as elites urbanas de origem 
A identidade teuto-brasileira pensada pelo intelectual Aloys Friederichs

alemã. Afirma ainda que os camponeses ficavam alheios à questão e as camadas médias das pequenas cidades do interior preferiam aderir à língua portuguesa "e com freqüência assumem posturas de 'renegados"'. Mesmo que seja relativizada esta afirmação, ela expressa uma tendência de comportamento e um alcance limitado da ideologia étnica. Além disso, deve-se levar em conta os diferentes matizes das proposições teóricas dos germanistas, influenciados estes por princípios religiosos, políticos ou de gerações. Alguns deles aproximavam-se mais da proposta de Koseritz, outros, como Oberacker, o consideravam "incapaz de proclamar com convicção a imprescindível autopreservação étnica" (Gertz, 1999, p.8); alguns se deixaram seduzir pelo nacional-socialismo, outros permaneceram arraigados em seus ideais construídos na tradição do II Reich alemão; uns vieram antes, outros depois. Levando em conta a extensão cronológica do desenvolvimento desta ideologia - praticamente 60 anos - e as influências no campo religioso e político sobre a elaboração do pensamento germanista, já se denota que este não possuía uma unidade fechada, que não se constituía de um corpo doutrinário compacto e coeso, o que lhe permitiu interpretações de nuances diferenciados e acalorados debates entre a intelectualidade que pensou a identidade dos teutos no Brasil.

Entre os germanistas iremos encontrar jornalistas como Karl von Koseritz, pastores como Hermann Dohms, editores como Franz Metzler, poetas e professores, como Otto Meyer, além de profissionais dos setores comercial e industrial como Aloys Friederichs. Cada qual buscou propagar suas idéias em seu círculo de influência por meio dos instrumentos que lhes eram oferecidos: a grande imprensa, publicações periódicas de menor alcance, livros, cancioneiros, discursos festivos. $\mathrm{Na}$ década de 30, o tema rendeu até duas teses acadêmicas: Die volkspolitische Lage des Deutschtums in Rio Grande do Sul (A situação étnico-política no Rio Grande do Sul), de Carlos Henrique Oberacker e Der brasilianische 
Haike Roselane Kleber da Silva

Integralismus, de Carlos Henrique Hunsche (Gertz, 1999, p.37). Friederichs se valeu dos espaços disponíveis no meio associativo, como liderança étnica e bom orador, além da imprensa, utilizando-se também dos meios editoriais independentes para divulgar suas idéias. Suas posturas fizeram-no mover-se com certa facilidade entre os teutos e os brasileiros até que a radicalização das identidades nacionais - no Brasil e na Alemanha - o fizeram calar.

O cerne do pensamento de Friederichs é a composição entre "amor ao Brasil" e "fidelidade ao Volkstum alemão", o que quer dizer cultivar um sentimento patriótico em relação ao país que acolheu a população imigrante, sem, contudo, perder as características étnicas que distinguem os alemães dos demais neste meio multiétnico. Esta noção foi desenvolvida na prática em suas atividades e na teoria em discursos festivos e publicações. A idéiamestra do pensamento de Friederichs pode ser encontrada, por exemplo, no cancioneiro que editou em 1922, denominado Liederbuch (Friederichs, 1927) tanto na apresentação intencionalmente redigida, como nas canções selecionadas. Em Grützmann (2003a), encontramos uma análise pormenorizada desta obra no que concerne aos pressupostos que a envolvem. Alinhado ao ideário germanista, Aloys frisa, sempre que lhe parece apropriado, a necessidade da fidelidade e lealdade em relação à pátria brasileira para que se possa viver plenamente sua identidade étnica alemã. Por outro lado, a condição para que o teuto-brasileiro tenha uma atitude exemplar de cidadão é a manutenção de suas características étnicas - herdadas por laços familiares. Segundo Grützmann (2003a, p.3), Friederichs reproduz o argumento fundamental do germanismo, para o qual a etnicidade - e, no caso, a germanidade - é imutável, intrínseca ao indivíduo. Por isso, não deve transformar esta sua natureza, o que lhe tornaria um ser humano fraco e de pouca utilidade para a pátria.

Assim, conecta as duas partes que traduzem a categoria "teuto-brasileiro" numa relação de dependência de forma que

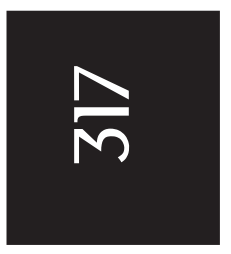


A identidade teuto-brasileira pensada pelo intelectual Aloys Friederichs

nenhuma possa sobreviver sem a outra. Friederichs é, portanto, um ferrenho defensor da categoria "teuto-brasileiro" - própria ao pensamento germanista - para a qual o indivíduo conserva a nacionalidade alemã - que é definida por sua condição étnica, herdada pelo sangue - e a cidadania brasileira. Em seus escritos muitos deles antes construídos para serem ouvidos - encontramse, nas linhas e nas entrelinhas, os ideais defendidos por Friederichs - e por outros germanistas - de fortalecimento da identidade teutobrasileira, herança recebida do político Koseritz. Como pai do "teuto-brasileirismo", Koseritz

[...] propunha a integração política, a luta pelo reconhecimento dos direitos de cidadania, a fidelidade à nova pátria e a contribuição do "trabalho alemão" para o desenvolvimento brasileiro e, ao mesmo tempo, defendia o direito à peculiaridade étnica, isto é, Deutschtum. (Seyferth, 2000, p.299).

A tônica de seu discurso estava na integração política dos imigrantes alemães, na medida em que a cidadania ainda não havia sido garantida, principalmente aos acatólicos. $\mathrm{Na}$ virada para o século XX, novas condições e influências foram moldando a categoria "teuto-brasileiro", recebendo diferentes acentos, enfoques e nuances de interpretação.

Como propagador da idéia do teuto-brasileirismo, Friederichs considera-se e aos seus semelhantes "cidadãos do Brasil de origem alemã, de sangue alemão"; que os mesmos têm "tão forte participação no desenvolvimento econômico desta bela e maravilhosa terra" e "discreção na atuação política". ${ }^{10}$ É seu dever, como de todos os teuto-brasileiros, fomentar em seus filhos o amor à pátria - filhos da terra brasileira, mas de sangue alemão. ${ }^{11}$ Por isso, é preciso também cultivar o amor e a fidelidade ao modo de ser alemão, ao seu caráter, à sua essência, à sua raiz cultural ancestral, o que pode ser entendido como etnia. Ambos - pátria e etnia - se equivalem em valor à família e à religião.

Anos 90, Porto Alegre, v. 12, n. 21/22, p.295-330, jan./dez. 2005 
Este era o seu "programa de vida" (Lebensprogramm), pelo qual batalhou na atividade associativa, pelo qual se empenhou na atuação oratória: "o fiel cultivo de nossa germanidade tem os mesmos direitos ao lado da fidelidade ao amor à pátria brasileira". Considerava, portanto, totalmente natural e justificável o empenho e dedicação em favor da pátria (Vaterland), o país de nascimento - ou de naturalização -, a terra natal (Heimat) e o apego à essência cultural herdada dos antepassados. Entendido como herança, o Volkstum é imutável, não importa onde se tiver nascido,

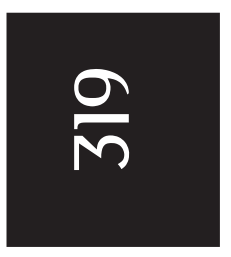
não importa qual for sua pátria (Vaterland) e a sua terra-natal (Heimat).

Apesar da constante referência à igual fidelidade aos dois elementos - Volkstum e Vaterland - a ênfase do discurso de Friederichs - ao menos até 1928 - parece recair sobre a preservação do apego ao primeiro. $\mathrm{O}$ valor concedido ao Volkstum pode ser evidenciado na seguinte passagem: "nosso Volkstum alemão é o solo materno fornecedor de forças no qual os nossos fios da alma e da índole constantemente precisam imergir para um novo fortalecimento, do qual nós retiramos as melhores seivas e forças, que nós colocamos à disposição de nós mesmos para a bênção da pátria brasileira" (Friederichs apud Grützmann, 1999, p.99). A avaliação de Friederichs carrega, como todo o discurso do Deutschtum, uma idéia de superioridade germânica: do trabalho alemão, da índole alemã, dos valores, do modo de ser, da cultura. Considero que o fato de ser um alemão nato e ter emigrado no final do século XIX tenha influenciado essa ênfase em seu discurso. Considero também importante a constante atualização de seu sentimento de pertença que as diversas viagens que realizou à Alemanha propiciaram.

À preservação da germanidade, Friederichs dedica a maior parte de sua fala e de sua atuação pública. A razão disso pode se encontrar no fato de que há, no mesmo período da atuação de Friederichs, um movimento em sentido contrário de constituição 
A identidade teuto-brasileira pensada pelo intelectual Aloys Friederichs

da identidade brasileira a partir da integração e assimilação cultural dos imigrantes à sociedade "multiétnica" de dominação lusa. Assim, a luta dos germanistas se dá no sentido de fortalecer a identidade "original", valorizar as características "intrínsecas" aos "de origem" alemã, evitar que o imigrante ou o "brasileiro de sangue alemão" abandone ou renegue sua essência. Isso não deve implicar em desobediência ao Estado ou às instituições políticas: graças às virtudes próprias à essência, ao caráter do povo (Volkstum), ele cultiva a fidelidade à pátria. Da mesma forma, só será um bom cidadão brasileiro de sangue alemão aquele que dá o devido valor ao seu Volkstum. Em um de seus discursos, enfatiza o seguinte:

Quem não ama mais sua pátria, é um pobre desorientado homem; quem não ama mais e não cultiva mais seu Volkstum, quem não aumenta e guarda os tesouros, que são elevados e guardados no Volkstum ancestral cotidianamente através do uso da língua materna, através de uma canção popular, através de um bom livro, ficará internamente pobre e sempre mais pobre. E junto a este processo de empobrecimento interior em uma única geração a pátria Brasil também será traída; pois nós podemos apenas trabalhar entusiasmados para o progresso da pátria, se se deixar forte e inteiro nosso modo de ser ancestral, nossa liberdade interior e nosso Volkstum. ${ }^{12}$

Em certos momentos, Friederichs valeu-se de apelos ainda mais diretos para persuadir sua comunidade de ouvintes (ou leitores). É o caso da seguinte ameaça:

A quem entre nós, de raça alemã e de sangue alemão, não repicarem os sinos da velha pátria de origem durante as sublimes comemorações do centenário do trabalho alemão; quem não ouve no seu íntimo a voz da venerável, tantas vezes humilhada, mas sempre grande e orgulhosa mãe

Anos 90, Porto Alegre, v. 12, n. 21/22, p.295-330, jan./dez. 2005 
Germânia; quem não confessa com alegria e orgulho o Volkstum alemão, esse se separe de nós, nós lhe ajudamos a fechar a porta atrás de si, nós não derramamos uma única lágrima por ele. ${ }^{13}$

A defesa do Volkstum é claramente expressa nos discursos, com ênfase maior em um ou outro aspecto, dependendo também do tema-motivação do texto. Em 1911, quando ocorre a inauguração do campo de jogos do Turnerbund (Spielplata), Friederichs acentua o vigor (Volkskraft) como um componente étnico enraizado em todo o alemão, no país ou no "além-mar", imigrante ou descendente:

Com cada emigrante alemão trabalhador-feliz vai junto um pedaço do vigor alemão para os países estrangeiros, triunfando sobre os perigos da vida, que fomenta a cultura por todos os lugares onde coloque seus pés. [...] o original, nunca negado vigor alemão. Sim, ele também aqui deu bom resultado até os dias de hoje, nos descendentes desses primeiros imigrantes, naqueles que só mais tarde vieram, também dará bons resultados nos que vierem para cá nos novos tempos. ${ }^{14}$

Esse discurso ajusta-se perfeitamente ao ideário germanista, que defende que os imigrantes e seus descendentes possuem uma essência compartilhada como povo alemão, a mesma identidade étnica e nacional daqueles que habitam o território da Alemanha. Embora esta identidade seja herdada, imutável - "um dado inexorável do destino" (Grützmann, 2003b, p.124) - e mantenhase nas gerações nascidas noutro continente - o que aparece claramente também nos discursos de 1923 e 1927 -, necessita ser cuidadosamente preservada e constantemente cultivada, de modo que não seja perdida: 
A identidade teuto-brasileira pensada pelo intelectual Aloys Friederichs

[...] magnífica herança: se nós não a guardarmos e cultivarmos, então ela será devagar, mas seguramente esquecida. Cada patrimônio, seja ele o mais precioso, será desperdiçado. Nesta intuição, já nos adverte com insistência nosso maior poeta: "O que tu herdaste de teus pais, apropria-te disso para possuí-lo". Ainda temos o vigor alemão, ele ainda pulsa em nossa colônia alemã, em nossas escolas, comunidades, federações e sociedades. ${ }^{15}$

A fundamentação do pensamento de Friederichs pode ser traduzida nos critérios primordialista e culturalista da etnicidade (Poutignat; Streiff-Fenart, 1998), na medida em que a identidade que forma o grupo étnico é considerada herdada por laços de sangue, o que não garante, porém, o pertencimento ao grupo. Para isso, é necessária a manutenção de um conjunto de elementos culturais que os distinguem dos demais. Entre eles está o cultivo da ginástica alemã - Turnen - e da canção alemã - Lied. Friederichs defende que o Turnen é um meio eficaz de preservação das virtudes e de fortalecimento da identidade. Também a canção popular alemã (Lied) é entendida como um instrumento adequado e privilegiado para a sensibilização das pessoas, conscientização e incorporação dos valores a preservar.

Friederichs recomenda que se mantenha, mesmo em situações adversas, o orgulho de pertencer à etnia alemã. Reforça, contudo, a necessidade de incorporação do binômio "amor ao Brasil, fidelidade ao Volkstum" que caracterizou sua intervenção como intelectual e liderança teuta. A ênfase no "amor ao Brasil" parece ser um diferencial no discurso de Friederichs na medida em que, de forma geral, o discurso germanista não incita o desenvolvimento de um sentimento subjetivo para com a pátria brasileira. Segundo Grützmann (2003b, p.129), a categoria "teuto-brasileiro" delimita objetivamente os critérios de identificação, conciliando "o pertencimento ao povo alemão e a situação existencial dos 
imigrantes e seus descendentes no Brasil". Para esta caracterização, a autora utilizou-se do pensamento de Hermann Dohms, liderança religiosa e intelectual teuta nas décadas de 20 e 30. Do mesmo período são os escritos de Hans Raunegger, dos quais Grützmann (2003b, p.129) conclui que "a condição alemã decorre de vínculos culturais e biológicos, sendo considerada atávica; a denominação 'brasileiro' restringe-se ao vínculo político - a cidadania -, que, nesse discurso, engloba apenas os seguintes aspectos: pagamento dos impostos, respeito às leis, cumprimento dos deveres civis e defesa da pátria". Isso não quer dizer que Friederichs fosse absolutamente original. Acredito que tenha sido um discípulo de Karl von Koseritz, este sim um intelectual original. Mas Friederichs utilizou-se da visibilidade alcançada na direção de associações do grupo étnico para ressaltar os aspectos que mais lhe convinham no germanismo e assim produzir a identificação de sua pessoa com uma certa forma de compreensão da identidade teuto-brasileira. Nesse sentido, quando Friederichs usa o termo "pátria adotiva" para referir-se ao Brasil, iguala-o ao conceito de Heimat - terra-natal, lugar da intimidade, do aconchego, "querência" - lugar que aprendeu a amar "verdadeira e sinceramente". Diferente daqueles que vêm para passar um período,

[...] nós outros, que cotidianamente e em trabalho autóctone com suor honesto e amor pela terra brasileira, merecemos a carta de naturalização, e todos vocês aos quais é concedida a carta de naturalização por direito de nascimento, nós não queremos falar de gratidão pela hospitalidade, nós queremos falar de amor, de amor à maneira alemã, queremos manifestá-lo à pátria, à pátria adotiva, à nova pátria Brasil. ${ }^{16}$

Ao responder uma carta, em janeiro de 1924, a um amigo na Alemanha, que sugeria a Friederichs que voltasse a viver naquele país, Aloys confessa ter construído sua Heimat em Porto Alegre: 
A identidade teuto-brasileira pensada pelo intelectual Aloys Friederichs

Minha esfera de atividade comercial e na germanidade está aqui; aqui me tornei uma força motora em meu trabalho e através dele, a qual, por que ela produziu e ainda produz, ainda vale. E por isso Porto Alegre se tornou minha Heimat, a qual eu também me liguei intimamente, que não apenas são considerações por vantagens materiais. Isso já estava claro para mim antes da guerra. E agora, tu sabes bem, que eu também não quero visitar minha terra-natal junto ao Mosela no lado esquerdo do Reno. (Friederichs, 1924).

Porto Alegre "tornou-se" a Heimat de Friederichs por escolha, por tê-la construído desta forma; o Brasil, sua Vaterland, sua pátria, a quem devia fidelidade política, comportamento cívico e amor. Em nenhum momento se referiu a ele como Gastland - país hospedeiro - por assumir sua condição definitiva como cidadão brasileiro. Não admitia, porém, que tivesse que renegar sua cultura ancestral para que pudesse ter plena cidadania. Pelo contrário, eram suas características étnicas - consideradas intrínsecas, herdadas pelo sangue, próprias ao "espírito" e ao "caráter" alemão que forneceriam as virtudes necessárias - laboriosidade, fidelidade, vigor - para a efetiva vivência da cidadania brasileira.

$\mathrm{Na}$ conjuntura de 1937, quando o nacional-socialismo opera de forma agressiva sobre as populações de imigrantes alemães e descendentes, é necessário reafirmar, e talvez de forma mais contundente do que antes, o caráter hifenizado de sua identidade, a fidelidade ao Brasil, a escolha deste como pátria, o apego apenas cultural à Alemanha. É preciso também estabelecer claramente as diferenças entre "nós e eles": os teuto-brasileiros e os "alemães do reino" ou os "alemães novos". Em um manifesto publicado naquele ano, denominado de Grundsächtzliche Betrachtungen zur Anschlussfrage (Considerações a respeito da questão da anexação), Friederichs, Englert e Bercht (1937) tentam mostrar que, para os teuto-brasileiros, a pátria (Heimat) não é a Alemanha, mas o Brasil; que os teuto-brasileiros não são "alemães no exterior", mas brasi-

Anos 90, Porto Alegre, v. 12, n. 21/22, p.295-330, jan./dez. 2005 
leiros de sangue alemão. Trata-se de uma resposta a entidades estrangeiras ligadas ao nacional-socialismo que tentam cooptar as instituições do grupo étnico para sua causa. Neste sentido, os autores do manifesto buscam convencer aos leitores de que qualquer ligação que não seja de ordem cultural com as instituições alemãs redunda em alinhamento político com o nacional-socialismo. E este - o nacional-socialismo - quer mais de seus "compatriotas" alemães que vivem fora das fronteiras da Alemanha. O manifesto cita comentários do coordenador da Organização do NSDAP no

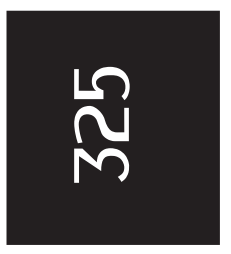
Exterior que dizem o seguinte: "Pois quem quer ser hoje alemão, deve ser nacional-socialista"; e ainda que "hoje se sabe em todo o mundo, que os alemães e também os alemães no exterior são e permanecem nacional-socialistas" (Friederichs; Englert; Bercht, 1937, p.9). Os signatários do manifesto rejeitam tais afirmações e confirmam seu trabalho pela germanidade como um serviço em favor do Brasil. Não admitem, portanto, que sua demonstração de fidelidade ao caráter/etnicidade alemã seja confundido com lealdade política, principalmente lealdade ao nacional-socialismo.

No final dos anos 30, portanto, o discurso de Friederichs acaba pendendo mais para a afirmação da cidadania brasileira do que para a preservação da germanidade. Neste período, é mais importante declarar-se diferente do alemão "do reino", daquele que tem cidadania e nacionalidade alemã (Staatsangebörigkeit). A radicalização do nacionalismo alemão, do germanismo e do nacionalismo brasileiro induz a uma tomada de posição - que não é nem por um nem por outro dos lados, mas uma última tentativa de reafirmar uma identidade hifenizada.

\section{Teutonic identity thought by the intellectual Aloys Friederichs}

Abstract. The Brazilians of German descent ethnical group has produced, in Southern Brazil, several leaderships in many aspects of social live. These leaderships were responsible, by their turn, for the production and reproduction of the interpretation about their ethnical group and others. This paper analyses the discourse 


\section{A identidade teuto-brasileira pensada pelo intelectual Aloys Friederichs}

of J. Aloys Friederichs - a leading figure among Brazilians of German descent about the identity of his group.

Keywords: Germanity. Ethnicity. Ethnic leadership.

\section{Notas}

${ }^{1}$ Além dos trabalhos citados na listagem que segue no parágrafo, lembro também do texto de Rambo (1994. p.43-53).

${ }^{2}$ Instituição central da administração da Igreja Evangélica de Confissão Luterana no Brasil no estado.

${ }^{3}$ O Partido Colonial foi uma agremiação criada em 1890, que visava fazer frente às demais facções políticas do Rio Grande do Sul na defesa dos interesses da região de colonização alemã. Teve fraca atuação até por não conseguir afirmar-se como representante dos "alemães", nem tampouco dos "colonos", uma vez que não levou em conta a heterogeneidade do grupo (diferenças sociais, religiosas e regionais). A partir de 1893, não se faz mais menção a tal organização partidária nos jornais alemães de Porto Alegre (Gertz, 1993, p.61-74).

${ }^{4}$ Alberto Bins foi eleito vice-indentente em 1928; com a morte do intendente Otávio Rocha, assume o cargo que mantém até 1937.

${ }^{5}$ Este indivíduo foi objeto de estudo biográfico de minha tese de doutorado (Silva, 2005).

${ }^{6}$ Essa designação lhe servia em todos os seus significados: segundo Aurélio Buarque de Holanda Ferreira, "paredro" quer dizer "mentor, conselheiro, guia"; ao mesmo tempo, "dirigente de clube desportivo e mandachuva".

${ }^{7}$ É importante lembrar, como bem o fez Grützmann (2003b, p.117), que o germanismo não é um movimento exclusivo ao sul do Brasil, mas que também se manifestou em outros países que receberam imigração de alemães, como a Argentina e o Chile. Caracteriza-se, portanto, por ser um movimento desenvolvido "no exterior", junto às populações imigrantes, voltado aos de cultura alemã fora do território alemão.

${ }^{8}$ Aqui os autores citados parecem divergir um pouco. Seyferth (1981) trabalha com a idéia de uma auto-representação dos imigrantes e descendentes como teutobrasileiros baseada na ideologia étnica, embora afirme que a ênfase na identidade teuto-brasileira fosse dada pelas "elites locais" (SEYFERTH, 1999, p.75). Gertz (1998, p.33-34) critica-a por "incorrer no equívoco de pressupor que tudo o que os ideólogos do germanismo diziam era integralmente endossado pela totalidade da população de origem alemã". Para Gertz, o germanismo ou a ideologia étnica teuto-brasileira teve aceitação apenas no meio urbano e entre os que ascenderam economicamente.

Anos 90, Porto Alegre, v. 12, n. 21/22, p.295-330, jan./dez. 2005 
${ }^{9}$ Seyferth (1981, p.34) explica que, no período de Bismarck, "o nacionalismo alemão tomou um caráter não liberal e paternalista, desvirtuado de algumas idéias mais importantes de 1813. Os intelectuais mais importantes dessa época aceitaram aos poucos a sociedade autoritária, imposta pelos ideais militaristas prussianos, conservadora e culturalmente calcada nos valores do passado".

10 "Festrede bei der vom Verbande Deutscher Vereine in Porto Alegre veranstalteten Jahrhundertfeier der Unabhängigkeit Brasiliens” (Friederichs, 1928, p.17).

11 “Jahnfeier im Turnerbund Porto Alegre, am 13. August 1927” (Friederichs, 1928, p.40).

12 “25 Jahre Turnverein Cahy, 25. August 1923” (Friederichs, 1928, p.24).

13 "Festrede auf dem Jahrhundertfestkommers in Porto Alegre am 4. Oktober 1924" (Friederichs, 1928, p.37).

14 "Festrede bei Einweihung unseres Spielplatzes am 21. Mai 1911" (Friederichs, 1928, p.4).

${ }^{15} \mathrm{Id}$. ibid.

16 "Festrede auf dem Jahrhundertfestkommers in Porto Alegre am 4. Oktober 1924" (Friederichs, 1928, p.37-38).

\section{Referências}

AMMON, Wolfgang. Cartapara J. Aloys Friederichs. 7 dez. 1922. JAF 0189. Acervo Benno Mentz.

BERCHT, A.; ENGLERT, G.; FRIEDERICHS, J. A. Grundsätəlich Betrachtungen zur Anschlussfrage, 1937.

BREPOHL, Wilhelm. Arno Philipp: ein deutschbrasilianischer Politiker und Pfleger des Volkstums. Der Auslanddeutsche - Halbmonatsschrift für Auslanddeutschtum und Auslandkunde. Mitteilung des Deutschen AuslandInstituts, Stuttgart, Jahrg. XIII, n. 5, p.149-150, März, 1930. IberoAmerikanische Institut-Berlin.

COHEN, A. The lesson of ethnicity. In: SOLLORS, W. (Ed.) .Theories of ethnicity; a classical reader. New York: New York University Press, 1996. p.370384.

CORREIO DO POVO. Porto Alegre: Cia. Jornalística Caldas Júnior, 3 fev. 1928. JAF 0009. Recorte. Acervo Benno Mentz.

DEUTSCHE POST. São Leopoldo, 3 fev. 1928. JAF 0014. Recorte. Acervo Benno Mentz.

Anos 90, Porto Alegre, v. 12, n. 21/22, p.295-330, jan./dez. 2005 
A identidade teuto-brasileira pensada pelo intelectual Aloys Friederichs

DEUTSCHE WACHT - NATIONAL-DEUTSCHE ZEITUNG. Buenos Aires, 13 fev. 1923. JAF 0614. Recorte. Acervo Benno Mentz.

DIÁRIO DE NOTÍCIAS. Porto Alegre, 3 fev. 1928. JAF 0010. Recorte. Acervo Benno Mentz.

DREHER, M. (Org.). Hermann Gottlieb Dohms; textos escolhidos. Porto Alegre: EDIPUCRS, 2001.

FÉLIX, L. Religião e política: os teuto-brasileiros e o PRR. In: MAUCH, C; VASCONCELOS, N. (Org.). Os alemães no Sul do Brasil; cultura, etnicidade e história. Canoas: Ed. ULBRA, 1994. p.77-85.

FORTES, A. Nós do quarto distrito; a classe trabalhadora porto-alegrense e a era Vargas. Rio de Janeiro: Garamond, 2004.

FRIEDERICHS, J. A. Carta para Oscar, 19 jan. 1924. JAF 2079. ABM.

(Org.). Liederbuch. Porto Alegre: Typographia Mercantil, 1927.

Reden bei Feiern der Turnerschaft und des Verbandes Deutscher Vereine. São Leopoldo: Rotermund \& Co., 1928.

GANS, M. Presença tenta em Porto Alegre no século XIX (1850-1889). Porto Alegre: Editora UFRGS; ANPUH/RS, 2004.

GERTZ, R. O aviador e o carroceiro: política, etnia e religião no Rio Grande do Sul dos anos 1920. Porto Alegre: EDIPUCRS, 2002.

A construção de uma nova cidadania. In: MAUCH, C.;

VASCONCELOS, N. (Org.). Os alemães no sul do Brasil; cultura, etnicidade e história. Canoas: Ed. ULBRA, 1994. p.29-40.

O fascismo no Sul do Brasil. Porto Alegre: Mercado Aberto, 1987. 1999.

(Org.). Karl von Koseritž, seleção de textos. Porto Alegre: EDIPUCRS,

Operários alemães no Rio Grande do Sul (1920-1937) ou Friederich Kniestedt também foi um imigrante alemão. Revista Brasileira de História, São Paulo. v.6, n.11, p.75-84, set. 1985/fev. 1986.

O perigo alemão. 2. ed. Porto Alegre: Ed. UFRGS, 1998.

Anos 90, Porto Alegre, v. 12, n. 21/22, p.295-330, jan./dez. 2005 
GRÜTZMANN, I. "Em todo o amor ao Brasil, manter a fidelidade ao modo de ser alemão": as canções em língua alemã e a construção de identidades. In: SIMPÓSIO NACIONAL DE HISTÓRIA DA ANPUH, XXII, 2003, João Pessoa. Anais eletrônicos do XXII Simpósio Nacional de História da ANPUH. João Pessoa: UFPB, 2003a.

O carvalho entre palmeiras: representações e estratégias identitárias no germanismo. História - Unisinos, v.7, n.8, p.115-169, 2003b.

- A mágica flor azul: a canção em língua alemã e o germanismo no Rio Grande do Sul. Porto Alegre, 1999. Tese (Doutorado em Letras) - Pontifícia Universidade Católica do Rio Grande do Sul, 1999.

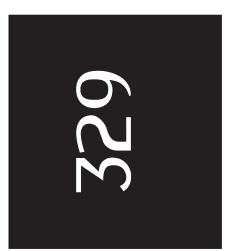

KOSERITZ DEUTSCHE ZEITUNG. Porto Alegre, 18 jun. 1895. Acervo Benno Mentz.

Porto Alegre, 20 nov. 1901. Acervo Benno Mentz.

Porto Alegre, 21 abr. 1902. Acervo Benno Mentz.

LESSER, J. A negociação da identidade nacional: imigrantes, minorias e a luta pela etnicidade no Brasil. São Paulo: Editora UNESP, 2001.

MEYER, D. Identidades traduridas; cultura e docência teuto-brasileiro-evangélica no Rio Grande do Sul. Santa Cruz do Sul; São Leopoldo: EDUNISC; Editora Sinodal, 2000.

POUTIGNAT, P.; STREIFF-FENART, J. Teorias da etnicidade; seguido de grupos étnicos e suas fronteiras de Fredrik Barth. São Paulo: UNESP, 1998.

RAMBO, A. Nacionalidade e cidadania. In: MAUCH, C.; VASCONCELOS, N. (Org.). Os alemães no sul do Brasil: cultura, etnicidade e história. Canoas: Ed. ULBRA, 1994. p.43-53.

SCHULZE, H. Estado e nação na história da Europa. Lisboa: Editorial Presença, 1997.

SEYFERTH, G. A colonização alemã no Brasil: etnicidade e conflito. In: FAUSTO, B. Fažer a América; a imigração em massa para a América Latina. São Paulo: Edusp, 2000. p.173-313.

Cultura, 1981.

Nacionalismo e identidade étnica. Florianópolis: Fundação Catarinense de

Anos 90, Porto Alegre, v. 12, n. 21/22, p.295-330, jan./dez. 2005 
A identidade teuto-brasileira pensada pelo intelectual Aloys Friederichs

SILVA, Haike Roselane Kleber da. A trajetória de uma liderança étnica: J. Aloys Friederichs (1868-1950). 2005. Tese (Doutorado em História) - Programa de Pós-Graduação em História, Universidade Federal do Rio Grande do Sul, Porto Alegre, 2005.

TURNERBUND. Livro de Protocolo de Atas. Porto Alegre, Assembléia Geral, 16 dez. 1929. Memorial Sogipa.

WEBER, M. Economia e sociedade; fundamentos da sociologia compreensiva. 3. ed. Brasília: Ed. UnB, 1994.

WILLEMS, E. A aculturação dos alemães no Brasil; estudo antropológico dos imigrantes alemães e seus descendentes no Brasil. Brasília: Cia. Ed. Nacional, 1980.

WOLFGANG, Ammon. Carta para J. Aloys Friederichs. 7 dez. 1922. JAF 0189.

Acervo Benno Mentz.

WOORTMANN, E. Identidades e memória entre teuto-brasileiros: os dois lados do atlântico. Horizontes Antropológicos, Porto Alegre, ano 6, n.14, p.205-238, nov. 2000.

Recebido em 31/05/2005.

Aprovado em 10/07/2005. 